\title{
MENINGKATKAN MOTORIK KASAR USIA PRASEKOLAH MELALUI GERAKAN TARI PADA KELOMPOK B TK NURANI
}

\author{
Endang Tri Surdayanti ${ }^{1}$, Kusniati Nursika Sahara ${ }^{2}$, Rohmalina ${ }^{3}$ \\ ${ }^{1}$ PAUD Bougenville Ceria, Lembang \\ 2 TK Nurani, Lembang \\ ${ }^{3}$ IKIP Siliwangi, Cimahi \\ 1endangts68@gmail.com, ${ }^{2}$ kusniatisahara@gmail.com, \\ 3 rohmalina@ikipsiliwangi.ac.id
}

\begin{abstract}
This research is aimed at increasing rough motor on early childhood. At early childhood, There are a lot of developmental aspects that must be stimulated and one of this is the rough motor movement. Children's rough motor movement is the ability of children in moving using big muscles. Nowadays there are schools that focused more on the smooth motor movement such as writing, cutting and others that is due to factors of parents and demands of calistung (reading, writing, and counting) to enter the basic education unit. Rough motor movements become abandoned, but researcher intended to increase children's motor movement, not only in smooth motor movement but also rough motor movement. One of the activity to increase children's rough motor movement is through dance activities for childrens. Through this dance movement, children's rough motor movement can be stimulated and children is given varied instruction, not only doing basic movements such as jumping, running and others but the childrens are also able to perform other dance movements accompanied with music. Therefore children is not only learning but also able to recognize fun dance movements.
\end{abstract}

Key words : early childhood, children rough motor movement, dance movement activity

\begin{abstract}
Abstrak
Penelitian ini bermaksud untuk meningkatkan motorik kasar usia prasekolah. Pada masa prasekolah, banyak aspek-aspek perkembangan yang harus distimulus salah satunya motorik kasar. Kemampuan motorik kasar pada anak adalah kemampuan anak menggerakan tubuh menggunakan otot-otot besar. Saat ini, banyak sekolah yang lebih fokus pada kemampuan anak dalam motorik halus seperti menulis, menggunting dan lain-lain,hal itu disebabkan faktor orang tua dan tuntutan calistung (membaca, menulis, berhitung) untuk memasuki satuan pendidikan dasar. Kemampuan anak dalam motorik kasar jadi terbengkalai,. Salah satu kegiatan menumbuhkan kemampuan motorik kasar anak diantaranya yaitu melalui kegiatan gerak tari untuk anak. Melalui kegiatan gerak tari, motorik kasar anak dapat terstimulus dan memberikan suatu pembelajaran yang bervariasi pada anak, tidak hanya melakukan
\end{abstract}




\section{JURNAL CERIA}

ISSN : 2614-6347 (Print) 2614-4107 (Online)

Vol.1 | No.3 | Mei 2018

gerakan dasar seperti melompat dan berlari namun anak dapat melakukan berbagai gerakan tari dengan lagu. Gerakan tari yang dilakukan tidak hanya untuk belajar tetapi anak juga dapat mengenal gerakan-gerakan tari yang menyenangkan.

Kata Kunci: usia prasekolah, motorik kasar dan gerakan tari

How to Cite: Surdayanti, E.T., Sahara, K.N., Rohmalina. (2019). Meningkatkan Motorik Kasar Anak Usia Prasekolah Melalui Gerakan Tari pada Kelompok B di TK Nurani. Ceria, 2 (1), -XX.

\section{PENDAHULUAN}

Usia prasekolah adalah masa perkembangan untuk keberlangsungan manusia. Pada masa tersebut, keseluruhan manusia terbentuk, bukan hanya aspek kecerdasan yang terbentuk, namun kecapakan psikis yang mendasar dan dinamakan sebagai usia emas perkembangan (golden age).

Jika tumbuh kembang tersebut dirangsang maka akan tercapai. Aspek perkembangan motorik yaitu aspek yang dapat mengintegrasikan perkembangan aspek yang lain. Adapun kegiatan yang dapat meningkatkan motorik kasar anak adalah kegiatan gerakan tari. Menari yaitu mengekspresikan diri, dalam suatu gerakan dan untuk melatih kecerdasan serta menggali kreativitas yang siswa.

Gerakan tari atau menari dilakukan agar motorik anak mencapai kemampuan keterampilan, sikap dan apresiatif (Evi, 37 : 2018).Kegiatan menari efektif untuk usia prasekolah,karena anak punya potensi yang masih harus dikembangkan seperti aspek fisik, motorik, dan kreativitas.

Penelitian dengan kegiatan gerakan tari-tarian daerah, tentu saja setiap daerah mempunyai jenis tarian yang berbeda-beda. Tari daerah tersebut diambil dikarenakan dapat membudidayakan seni tari Indonesia dan bertujuan untuk membela negara bagi usia prasekolah.

Secara garis besar, pembelajaran motorik di sekolah meliputi pembelajaran motorik kasar dan halus. Menurut Decaprio (2013: 18) motorik kasar adalah gerakan tubuh yang menggunakan otot-otot besar atau sebagian besar otot yang ada dalam tubuh maupun seluruh anggota tubuh yang dipengaruhi oleh kematangan diri. Sedangkan pembelajaran yang diadakan di sekolah merupakan pembelajaran gerakan fisik dan koordinasi seluruh anggota tubuh atau sebagian. Contohnya : berlari, berjalan, melompat, menendang, berlari dan lain-lain.

Dengan begitu, maka kegiatan ini adalah gerak jasmani yang berpengaruh pada kematangan diri. Aktivitas motorik kasar misalnya: berlari, melompat, berjalan dan lain- lain.

\section{METODE}

Penelitian ini menggunakan Penelitian Tindakan Kelas (Classroom Action Research) dengan rencana tindakan yaitu proses tindakan pada siklus I dan siklus II (Heris, 2014). Pada siklus I di maksudkan untuk peranan kegiatan gerak tari, siklus II dimaksudkan untuk hasil penelitian proses dan tahu tentang peningkatan motorik kasar anak melalui gerak tari anak setelah dilakukan perbaikan dalam kegiatan anak yang didasarkan pada refleksi I. Kegiatan ini dilakukan empat tahapan yaitu : tahap perencanaan, tindakan, pengamatan, dan refleksi.

1. Tempat dan Waktu Penelitian

Sehubungan dengan pertimbangan secara empiris, bahwa yang diteliti terfokus pada proses yang diteliti yaitu pada proses tari. Penelitian dilakukan dengan berlokasikan di tempat peneliti mengajar dengan uraian sebagai berikut :

a. Tempat Penelitian

Di TK Nurani yang terletak Jl. Panorama,

b. Waktu Penelitian

Pada semester akhir tahun ajaran 2017-2018.

2. Subjek penelitian

Anak kelas B di TK Nurani dengan total 30 anak, 12 laki-laki dan 18 perempuan. Namun subjek penelitian yaitu 7 perempuan.

3. Data dan Teknik Pengambilan Data

Sumber data yaitu anak dan guru. 


\section{JURNAL CERIA}

ISSN : 2614-6347 (Print) 2614-4107 (Online)

Vol.1 | No.3 | Mei 2018

a. Jenis data yaitu kualitatif yang didapat dari lembar observasi dan wawancara

b. Dokumentasi yaitu data berdasarkan hasil pelaksanaan kegiatan gerak tari yang dilakukan anak.

c. Pengumpulan data :

Data tentang kondisi pelaksanaan kegiatan gerak tari anak diambil meliputi observasi terhadap guru dan anak.

4. Indikator Kinerja

Ditinjau melalui dua segi yaitu dari segi penerapan kegiatan gerak tari dan hasil pemahaman anak. Pertama, dari segi penerapan kegiatan tari minimal $85 \%$ penerapan pelaksanaan tindakan telah sesuai. Kedua, dari segi hasilnya apabila minimal $85 \%$ meningkat dalam melaksanakan kegiatan gerak tari.

\section{HASIL DAN PEMBAHASAN}

Penelitian di TK Nurani Jalan Panorama II yayasan pendidikan An-Nuur dengan siswa sebanyak 30 anak untuk kelompok B dan yang diteliti adalah 7 anak. Penelitian ini dilaksanakan karena kurangnya kegiatan motorik anak, terutama motorik kasar. Peneliti mencoba melakukan penelitian untuk meningkatan gerak tubuh anak dengan tari.

Dari hasil data observasi pada penerapan kegiatan gerak tari pada anak. Dilaksanakan dalam 2 siklus.

\section{a. Siklus I}

\section{Perencanaan}

Sebelum melakukan tindakan maka harus ada tindakan persiapan.

- Penyusunan RPPH dengan kegiatan gerak tari yang direncanakan dalam PTK.

- Membentuk kelompok

- Memberikan penjelasan mengenai bagaiamana cara melakukan gerakan tari

Pelaksanaan Tindakan

- Melaksanakan kegiatan sesuai yang sudah dibuat. Adapun langkahnya anak memperhatikan terlebih dahulu, lalu anak melakukan gerakan dan menirunya (tanpa musik), setelah anak menguasai gerakan tari barulah anak melakukan tari dengan musik
- Kegiatan penutup. Pada saat terakhir pelaksanaan gerak tari, guru mengevaluasi anak yang gerakannya masih belum sesuai dan dilakukan bimbingan lagi oleh guru

Observasi

- Peneliti mengamati langsung terhadap anak saat menari

Refleksi

- Dalam tahapan ini peneliti melakukan analisis data dari kegiatan tersebut. Dan melakukan evaluasi agar mendapat hasil yang diharapkan

b. Siklus II

- Sama dengan pada siklus I namun perencanaan kegiatan mendasarkan pada hasil refleksi pada siklus I sehingga lebih mengarah pada perbaikan pada pelaksanaan siklus I.

\section{Tabel 1}

rekapitulasi hasil kegiatan gerak tari anak kelompok B di TK Nurani

\begin{tabular}{|c|c|c|c|c|c|c|c|c|c|}
\hline \multirow[t]{2}{*}{ No } & \multirow{2}{*}{$\begin{array}{c}\text { Nama } \\
\text { Anak }\end{array}$} & \multicolumn{2}{|c|}{$\begin{array}{c}\text { Kondisi } \\
\text { Awal }\end{array}$} & \multicolumn{3}{|c|}{$\begin{array}{l}\text { Siklus } \\
\text { I }\end{array}$} & \multicolumn{3}{|c|}{ Siklus II } \\
\hline & & $a \quad b$ & $\mathrm{c}$ & $\mathrm{a}$ & $\mathrm{b}$ & $\mathrm{c}$ & A & B & $\mathrm{C}$ \\
\hline 1 & Echa & & & & & & & & \\
\hline 2 & Enden & & & & & & & & \\
\hline 3 & Nada & & & & & & & & \\
\hline 4 & Naya & & & & & & & & \\
\hline 5 & Rere & & & & & & & & \\
\hline 6 & Sasha & & & & & & & & \\
\hline 7 & Tasya & & & & & & & & \\
\hline
\end{tabular}

\section{KESIMPULAN}

Banyak kemampuan perkembangan anak yang harus ditumbuhkembangkan yakni aspek kognitif, moral dan agama, sosial emosional, fisik motorik, bahasa dan seni. Salah satu aspek yang dikembangkan yaitu fisik motorik anak. Aspek fisik motorik terdapat dua bagian yaitu kasar dan halus. Tari dapat dibudayakan melalui unsur seni, juga mengandung pembelajaran. Penelitian di TK Nurani disambut baik dengan anak. Meskipun 


\section{JURNAL CERIA}

ISSN : 2614-6347 (Print) 2614-4107 (Online)

Vol.1 | No.3 | Mei 2018

awalnya anak masih terlihat kaku dalam meniru yang diperlihatkan guru. Namun di siklus I dan siklus II terjadi perubahan dibandingkan sebelumnya. Dengan melaksanakan kegiatan tari anak mengenak kemampuan mereka dapat melakukan gerakan- gerakan tari.

\section{DAFTAR PUSTAKA}

Decaprio, R. 2013. Aplikasi Teori Pembelajaran Motorik di Sekolah. Yogyakarta: Divapress. Susilowati, E. Upaya Meningkatkan Motorik Kasar Usia prasekolah melalui Gerak Tari di Satuan Pendidikan Sejenis Mahardika. Jurnal PG PAUD IKIP Veteran.(download.portalgaruda.org/article. php?. gerak tari). Unduh 1 Mei 2018. 